\title{
‘No One Puts Baby In A Corner': Inserting My Self Into The Text
}

\section{Tom Cho}

While there is an increasing body of work that can be described as Asian-Australian literature, at this point in time, it comprises a fairly small pool of authors and texts. ${ }^{1}$ In fact, I have often been struck by how Asian-Australian literary production seems to be outstripped by literary criticism on the topic.

At the same time, this small but growing field of literature has been subject to some persistent issues, some of which are raised in the introduction to this panel. They include questions of delimitation, the prevalence of Asian-Australian autobiographical works, and tensions between artistic freedom and a sense of responsibility to Asian communities. Although Asian-Australian literature is in the early stages of its development, it has already become plagued by certain recurring issues.

Over the course of my writing career, I have been encouraged by the continued emergence of Asian-Australian literature but discouraged by the persistence of these issues. For example, at times, I have grappled with the possibility of exploring themes outside of my Asian-Australian identity. At the same time, I have also been excited by the fact that there are very few, if any, precedents in the field of Asian-Australian literature for the kind of fiction I am producing. Perhaps this sense that one has great opportunities to contribute to a developing field also encourages other writers; furthermore, perhaps emerging literatures tend to be especially open to emerging writers. Yet, this potentiality aside, I have often felt that working in this field of Asian-Australian literature requires considerable deftness of approach. Over the years, I have sought to be mindful of this field's recurring issues, yet not necessarily to feel answerable to them. I have also sought to produce work that is distinct from existing texts in the field without simply dismissing the validity of the field.

My own endeavours to describe my Asian-Australianness in my fiction have involved a route as unpredictable as my personal adventures with my identity. Over the last seven years, I have been writing a short fiction collection that explores my identity. However, my identity has changed somewhat during this period, with one of the most significant of these changes being my gender

\footnotetext{
${ }^{1}$ For example, the list of 'Asian Australian Writing in English' developed by the Asian Australian Studies Research Network features just 28 writers

(http://www.asianaustralianstudies.org/resources.html\#criticindex).
} 
transition. As a result, my collection has had to undergo many major changes too. Oh well - that's showbiz. In fact, given all of this, the title of my short story collection (if that itself doesn't change) seems quite apt: Look Who's Morphing.

Despite the major changes to my collection, a relatively stable feature of this project is its exploration of my identity via a unique and powerful lens: my engagement with popular culture. As a result, Look Who's Morphing includes many renderings of popular cultural texts and figures (primarily those of which I am a fan, such as the film The Sound of Music). Consider, for example, the opening of the following piece, 'Godzilla Vs. Me'. This was the first piece that I wrote for my collection:

Godzilla Vs. Me

One night, after an absence of about two years, Godzilla rampaged through Tokyo again. However, this time, Godzilla had changed.

He had acquired a combination of the best qualities of the world's lizards. His eyes now moved independently of each other so that he could follow objects without moving his head. His skin was thornier and he had sharp claws on his hands and feet. As he moved slowly through the busier streets of Tokyo, his skin changed colours.

In addition, Godzilla now had a tongue that was bright blue. Furthermore, this tongue was long with a sticky tip. As he looked down upon the streets below him, Godzilla sent out his blue tongue to capture cars and people to eat. ('Two New Godzilla Stories' 33)

Although my collection is full of such renderings, I am not very interested in examining my engagement with popular culture in terms of popular cultural 'references' or 'allusions'. In fact, rather than focusing on the insertion of popular cultural references in my collection, what especially strikes me about this collection is the literal insertion of my self into the text: in a range of stories from my collection, I appear in various 'universes' derived from popular cultural texts/canons. Thus, my story 'Godzilla Vs. Me' continues:

The day after Godzilla's rampage, Japan's prime minister telephoned me. The Japanese government was putting me in charge of an operation to capture Godzilla, dead or alive.

I had been appointed to this important job due to my extensive expertise in lizard-catching. ('Two New Godzilla Stories' 33)

Despite the insertion of my self into my collection - and the consistent use of my life as raw material - this paper is not focused on the area of autobiography. This is not due to any uneasiness I have about the preponderance of autobiographical works by Asian-Australian writers. Rather, it is because I am especially interested in examining the very act by which the writer enters the 
text, and the dynamics this act creates between writer and text. The remainder of this paper discusses this textual self-insertion as a method of describing my self (which includes my Asian-Australianness).

I will now outline a model that can be applied to this self-insertion. This model was developed in relation to fan fiction. Broadly speaking, fan fiction is fan-produced fiction that is based upon pre-existing texts/canons. For example, Star Wars fan fiction typically comprises short stories that are based upon the Star Wars universe and utilise existing characters and storylines. These days, fan fiction is typically circulated in fan communities via publication on the Internet.

Although I am presenting this paper today in my capacity as a 'writer', my engagement with popular culture in my fiction also makes explicit my position as a reader. Not surprisingly, this collapsing of boundaries between writer and reader is also reflected in fan fiction (which adds the further position of 'fan' into the mix). In fact, academic and fan fiction writer Ika Willis describes fan fiction as being generated firstly by 'a practice of reading' that reorients a canonical text (155). She claims that, through subsequently writing fan fiction, a reader/fan/writer can 'make space for her own desires in a text' (155) and share this reoriented text with others. Yet the reader/fan/writer is also a subject. This point is also evoked by Willis; she argues that this textual reorienting is prompted by 'the demands and desires brought to' these canonical texts by the producer's subjectivity (153).

Rather than taking a view of fan fiction that is overwhelmingly celebratory, Willis states that such reorientation can also become 'a way of negotiating the 'painful gaps' left in the encounter between a reader's 'felt desires' and the read text' (166). Following on from this - and taking into account a long history of questionable depictions of Asians in texts - I am reminded of Jessica Hagedorn's editorial introduction to the volume Charlie Chan Is Dead: An Anthology of Contemporary Asian American Fiction. Hagedorn begins her introduction by discussing Charlie Chan, the fictional Chinese-American detective who was the subject of various novels and films. In addition to employing pseudo-Confucian sayings, Charlie Chan was only ever played by white actors in make-up rather than by any performers of Asian background. Hagedorn describes Charlie Chan as 'our most famous fake "Asian" pop icon' (xxi). She also recalls: 'I grew up in the Philippines watching Hollywood movies featuring yellowface, blackface, and redface actors giving me their versions of myself' (xxii). This comment reflects the pain that we can sometimes experience when we encounter reflections of ourselves in texts. It points to a painful incongruence between one's desires, knowledge and experiences, and the texts that articulate contradictory perspectives. 
However, let us return to Willis' article on fan fiction. Although she discusses fan fiction's textual reorientation as a way to negotiate painful encounters with texts, Willis also identifies pleasure in producing fan fiction. She does this in terms of her role as a writer of slash (a form of fan fiction that develops same-sex relationships between characters in the original text). Willis describes herself as 'taking pleasure' not only in reorienting canonical texts but 'in scandalously acting as if it were natural to do so, as if all readings ... were equally possible' (168).

This bittersweetness, this combination of pleasure and pain, can be found in many of the pieces in my own short fiction collection. I would now like to present the opening to another piece from this collection. If you are a fan of the film Dirty Dancing (and who among us is not?), you may especially enjoy this excerpt:

\section{Dirty Dancing}

This is the summer of 1963 and everybody is calling me 'Baby'. I am at a resort with my Auntie Feng and Uncle Stan for a holiday. The resort is on a small island that is located 10 miles off the coast of North Devon where the Atlantic meets the Bristol Channel. My auntie and uncle think the resort is very exciting and they soon start getting involved in all the resort activities - golf, macramé, etc. Me, I think the only moderately interesting thing about the resort is Johnny Castle. Johnny is a dance instructor at the resort and he has a very nice body. As it turns out, Johnny and I end up rehearsing a mambo dance number together for a forthcoming show at the resort and so we start spending a lot of time with one another. In fact, one night, Johnny and I find ourselves alone in his cabin. At first, we are just talking about our favourite 80s television shows and pop songs. But there is something in the way that discussions of popular culture can bring people together and thus our discussion soon leads to Johnny and I having sex. The thing is, while Johnny looks very nice and all, I do not really feel very 'in the moment'. In fact, as Johnny is panting and thrusting, I feel very detached from the experience. It is like I am a bystander, looking on as someone else completely different is having sex with Johnny. And that someone else is a Caucasian man with a moustache. This man is tall and very well-built. He is wearing a leather cap and leather chaps. His name? Bruce. As Bruce reaches for Johnny's wrists, I take the opportunity to watch Bruce. I find myself admiring how Bruce makes his masculinity so overt. I also find myself admiring Bruce's muscular body. And Bruce is so confident when it comes to sex. He doesn't say anything; he just pushes Johnny's face into the pillow. In the end, I watch as Bruce and Johnny spend all night having the hottest sex you can imagine. ('Dirty Dancing' 163) 
Various layers of self-insertion are present in this piece. For example, I change roles to become a bystander who watches a sexual encounter between two men. In doing this, I begin a new story - one within the original story - that I insert my self into. Outside of the story's frame, I - the writer-have inserted my self both into the universe of the film Dirty Dancing and into my short story 'Dirty Dancing' (and thus into my short fiction collection).

An intermingling of pleasure and pain is reflected in the various layers of textual self-insertion in this story. For example, in the story itself, I seem detached from experiencing sexual pleasure and in fact I end up watching as a tall and well-built Caucasian leatherman steps into my place to have sex. Yet, in the final section of the story, I have not only become good friends with Bruce and Johnny but I triumphantly come of age in a parallel version of how the film Dirty Dancing ends:

After the resort holiday, Auntie Feng and Uncle Stan head back to their home in Hobart. I am due to catch a plane back to Melbourne. It is hard saying good-bye to Bruce and Johnny, who are staying on at the resort until the summer is over. We promise to keep in touch. My parents meet me at the airport. They are very happy to see me. As always, they literally pass me around like I am a baby. My mother holds me in her arms and exclaims over my fingers and toes and then she passes me to my father. As my father cradles me, he starts talking baby-talk. He says to me, 'What's your name, hmmm? What's your name? Can you say your name?' and then he tickles my foot. Given that my parents call me 'Baby', none of this is surprising. They have been treating me like this for years and I have never felt that it would ever change. However, this time, it somehow annoys me more than usual. I tell my parents that I am not a baby. But my mother only pokes at my belly button and tells me that I am a little Buddha. My father then holds me up in the air and proclaims that I will grow up to be prosperous and lucky. I find myself being unsure as to what to do. The insecure part of me tells me to keep the peace and go along with everything, the ambitious part of me tells me that being prosperous and lucky would be very nice, and the part of me that learnt dancing at the resort tells me that dancing - like pop culture discussions - brings people together. In the end, the part of me that learnt dancing at the resort wins out, and so I jump out of my father's arms and I say to my parents 'No one puts Baby in a corner' and I perform a big raunchy dance number after I say it and everyone else at the airport joins in and starts dancing in a raunchy way too.

My parents have no comeback for all of this. As a result, they have no choice but to come to terms with the fact that I am an adult. ('Dirty Dancing' 164-65) 
In addition to the pleasure and pain described in the story itself, a combination of pleasure and pain is also present outside of the story's frame. This piece is a comedic short story that has brought me artistic satisfaction, as well as professional achievement. In addition, it was pleasurable for me to 'slash' the overtly heterosexual overtones of the film Dirty Dancing - to turn this film into a decidedly more queer story. I am also a fan of this film - I own it on DVD and video and have watched it multiple times. I enjoy it both as an 80s film in which dancing provides a way to triumph over hardship and also as a coming of age story that I can, in my own way, relate to. However, to recall Willis, this film also evokes painful discrepancies between its textual content and my own experiences and desires. My self-insertion into this text is thus an ironic contrast to my inability to see other aspects of my self-including my Asian-Australianness - reflected in this film. This act of self-insertion may have an air of mischief and even defiance - 'No one puts Baby in a corner' — and yet one cannot forget that it is also a response to pain.

Textual self-insertion is a powerful form of literally 'inhabiting texts' to respond to what can sometimes be painful subject-text relations. In the case of my creative writing practice, this self-insertion speaks to my role not only as a writer and a reader but as a subject. Just as my engagement with popular culture in my creative writing makes explicit my position as a reader, the insertion of my self into the text makes explicit my position as a subject. For now, this self-insertion - with its strong engagement with popular culture, its method of making texts literally accommodate my self, and its ability to both articulate and respond to pleasure and pain - is the best way I know of to write my identity into being.

Tom Cho's short fiction collection in progress, Look Who's Morphing, will be published by Giramondo in 2009. He is writing this collection as part of his PhD in Professional Writing at Deakin University. His short stories have been published widely, with more recent pieces in HEAT and the Best Australian Stories series. Visit him at www.tomcho.com.

\section{Works Cited}

Cho, Natasha. 'Dirty Dancing.' HEAT 7 (2004): 163-65.

-. 'Two New Godzilla Stories.' Adventures in Pop Culture. Eds. Adam Carey, Simmone Howell and Sharon Shelley. Melbourne: Vandal, 2002. 33-37.

Cho, Tom. Look Who's Morphing. Sydney: Giramondo, in press. 
Hagedorn, Jessica. 'Introduction.' Charlie Chan Is Dead: An Anthology of Contemporary Asian American Fiction. Ed. Jessica Hagedorn. New York: Penguin, 1993. xxi-xxx.

Willis, Ika. 'Keeping Promises to Queer Children: Making Space (for Mary Sue) at Hogwarts.' Fan Fiction and Fan Communities in the Age of the Internet: New Essays. Eds. Karen Hellekson and Kristina Busse. Jefferson, North Carolina: McFarland and Company, 2006. 153-70. 